\title{
Variability of cranial morphometrical traits in Suffolk Down Sheep
}

\author{
Rodrigo de la Barra ${ }^{a}$, Andrés M. Carvajala ${ }^{\text {a }}$ María E. Martínez ${ }^{b^{*}}$
}

\begin{abstract}
The widespread use of measures and indices associated with the head for racial analysis suggests that such measures have a strong relationship with the underlying bone structure. Few studies analyse the variability of the bones of the head and the relationship with their external expression. The objective of this work was to identify and measure the magnitudes of the main skull parameters in Suffolk Down adult sheep. This study was carried out on sixteen adult Suffolk Down sheep skulls at INIA Butalcura. Their skeletons were obtained and digital morphometry was performed. Each skull was photographed from dorsal, ventral, lateral and nuchal views with a total of 28 parameters evaluated (10 dorsal, 5 ventral, 6 lateral and 6 nape). The results indicate that the externally observable variability in the cranial zone of a sheep cannot be extrapolated to the rest of the bony components of the cranial zone, either in length, width or height. It was observed that the variability of a cephalic dimension can be contrasted with the variability of individual bones that participate in a certain dimension as part of a plasticity adjustment mechanism independent of the genetic variability of each bone separately. The cranial dimensions are still useful in defining the productive potential of a sheep population; however, they should be taken cautiously for racial definitions, where the individual variability of the bones could be a better reflection of the genetic structure of the population and the dimensionality could be biased by adaptive plasticity.

Key words: morphology, sheep, skull, animal ethnology.
\end{abstract}

\section{INTRODUCTION}

The body architecture of an animal biotype is the result of several factors that influence the predominant gene pool of a population and the expression of the characteristics that codify these genes (Thiagarajan and Jayashankar 2012). As a consequence, the animal architecture of sheep has been used for racial characterisation (Álvarez et al 2000, Riva et al 2004, Herrera and Luque 2009, Parés et al 2010, Bravo Sepúlveda 2010, De la Barra et al 2016, Baranowsky 2017). Zoometric indexes have also been used for this purpose, especially cephalic ones, because the cranial zone would be less influenced by environmental and management factors (Parés et al 2010, Özcan et al 2010, Ilayperuma 2011, Mohamed et al 2016), given that aspects such as the founder effect, hybridisation, inbreeding, and selection itself would alter animal body architecture by privileging certain genetic combinations in the offspring to the detriment of other gene mixtures (Sierra 2001, Latorre et al 2011, Chirinos 2011, De la Barra et al 2016). In this regard, the dimensions of the skull are those that allow a better taxonomic affiliation of an animal, and can even provide valuable information about the changes that occur over time in a population as a result of selection (Brüenner et al 2002, Cobb \& O'Higgins 2007, Parés et al 2010, Ilayperuma 2011). In this way, several authors point out that the main racial differentiators are found in the head of the animal (Aparicio 1960, Sánchez Belda 1964, Sotillo and Serrano 1985, Agüera et al 1988, Miró et al 1988,

Received: 02.05.2019.

Accepted: 02.09.2019.

anstituto de Investigaciones Agropecuarias, INIA Remehue, Osorno, Chile.

'Instituto de Investigaciones Agropecuarias, INIA Butalcura, Chiloé, Chile.

*Corresponding author: ME Martínez; eugemartinez.inia@gmail.com
Parés et al 2010), that is, the differences at the skull level are more defining of a breed than those found in the rest of the skeleton. Thus, craniocephalic topography allows obtaining topometric data that facilitate breed discrimination (Miró et al 1988, Mohamed et al 2016).

Despite the aforementioned, the skull in mammals is a complex of assembled bones with great adaptive capacity (Ravosa et al 2000, Thomason et al 2001), which could indicate a certain degree of variability at the level of its components. This could allow a greater specificity when using body measurements or zoomometric indexes in breed evaluation. With regard to animal selection, it is necessary to consider that, in the absence of other means of selection, morphology is an essential visual characteristic to differentiate and select biotypes, since it allows projecting the distinctive attributes of the corporality of an animal population in their offspring using such phenotypic criteria (Sierra 2001). In this sense, several authors agree that biological functionality is conditioned by the underlying form of the animal biotype (Bravo and Sepúlveda 2010, Chirinos 2011, De la Barra et al 2016, Macedo et al 2016, Popoola and Oseni 2018).

Thus, it is relevant to generate detailed information about the cranial parameters of the sheep to determine if the externally observed aspects are confirmed in the internal cranial structure, making the diagnosis and racial evaluation more accurate. The working hypothesis was that the variability of the skull components is similar to that of their total dimensions. The objective of this work was to identify and measure the magnitudes of the main skull parameters in adult Suffolk Down sheep.

\section{MATERIAL AND METHODS}

The present study was performed on sixteen skulls extracted from the skeletons of adult Suffolk Down sheep from the research flock of INIA Butalcura. Suffolk Down 
was used since it is a selected and widely distributed breed that allows its measurements to be confirmed by different researchers, and at the same time it can be used as a comparison pattern with other breeds. All the evaluated animals were females between 7 and 8 years of age. The weight of the animals varied between 80 and $90 \mathrm{~kg}$. The skulls came from 16 sheep unrelated to each other. The animals corresponded to females selected according to racial origin that came from different hatcheries and were integrated as a basal breeding nucleus in a plant. Their offspring were later selected by birth weight and weaning weight. However, these selection criteria were not applied to the selection. The skeletons had no anomalies or evidence of diseases that affected their normal development. To eliminate the remains of fat, meat and connective tissue, the skeletons were macerated in water with the addition of potassium hydroxide, using the technique of Olopade and Onwuka (2004), subjecting them to heating at $100{ }^{\circ} \mathrm{C}$ for 60 minutes. Subsequently, a water change was made and they were subjected again to the same temperature and time. Once cleaned, digital morphometry was performed on the skulls. Each skull was photographed from four angles (dorsal, ventral, lateral and nape) using a digital camera installed in a lectern, and a measurement scale was included next to each skull. The set of photographs was digitally measured using tools from the Power Point program. Twenty-eight parameters were measured (11 dorsal, 5 ventral view, 6 lateral and 6 nape view) (figure 1) and analysed using the Excel program. The normality of the data was analysed through the Llilie test (Kolmogorov Smirnov). The parameters to be evaluated, which were defined by Choudhary and Singh (2016), are detailed below:

\section{Dorsal view}

1. Lsk: Distance between the highest points of the parietals to the middle of the rostral margin of the incisive bone.

2. Wcr: Maximum distance between the bases of the horn buttons.

3. Lfa: Distance from the frontonasal suture to the centre of the incisive bone.

4. Wfa: Distance between the caudal extents of the orbital rims.

5. Lna: Distance from the central point of the frontonasal suture to the rostral end of the internasal suture.

6. Wna: Maximum distance across the nasal bones or maximum distance between the nasomaxillary sutures.

7. Lfr: Maximum length between parietofrontal suture and frontonasal suture.

8. Lfrs: Length of the frontal suture.

9. Ls: Length of the parietal bone.

10. Ws: Maximum distance between the zygomatic arches (total head width)

Ventral view

11. LBsk: Distance between the midpoints of the dorsal margin of the foramen magnum to the level of the middle point of the rostral margin of the incisive bone.
12. Lpa: Distance measured from the rostral mid sutured line of incisive bone to the caudal nasal spine of the palatine bone.

13. Wpa: Maximum distance at the horizontal plate of palatine bone behind the last molar tooth.

14. Hfm: The distance between the midpoints of the dorsal-ventral rims of the foramen magnum.

15. Wfm: The maximum distance between the two occipital condyles.

Lateral view

16. Lo: The perpendicular distance between the supraorbital and infraorbital margins of the orbit.

17. Wo: The horizontal distance between the rostral and caudal margins of the orbital rim.

18. Lpm: Maximum length of premaxilla.

19. Lma: Length of maxilla.

20. Hpm: Height of premaxilla.

21. Hma: Length of lacrimal.

Nape view

22. Hoc: Distance from base of the occipital condyle to the starting point of sagittal crest.

23. Wic: Width between the lateral ends of the occipital condyles.

24. Wipc: Width between the lateral ends of the paracondylar process.

25. Hpa: Maximum height of parietal.

26. Wpa: Maximum width of parietal.

27. Woc: Maximum point of parietal to the foramen magnum.

\section{RESULTS AND DISCUSSION}

The values of the measurements made on the sheep skulls evaluated are shown in table 1 . The dimensions of length, width and height of the head are determinant from the point of view of racial qualification and evaluation. In this way, the length and width of the head and skull are variables widely used in breed evaluation (Aparicio 1960, Sánchez Belda 1964, Sotillo and Serrano 1985, Agüera et al 1988, Miró et al 1988, Parés et al 2010, Mohamed et al 2016, Macedo et al 2016). However, this does not occur with height, since it is a dimension that is difficult to measure and, therefore, it is only qualitatively qualifiable by describing the imaginary triangle that occurs between the observable height and the length of the head.

The support behind each of these dimensions responds to different bone structures and must be analysed in detail to interpret the variations of these dimensions in different animals (Ravosa et al 2000, Thomason et al 2001) since it can be determined by the variability of a bone or the cumulative variation of all of them.

The total observable cephalic length from the dorsal view corresponded on average to $23.83 \mathrm{~cm}$, ranging between 21.42 and $27.03 \mathrm{~cm}$, with a coefficient of variation of 
Table 1. Values of skulls parameters in adult Suffolk Down sheep.

\begin{tabular}{|c|c|c|c|c|c|}
\hline Variable & $\begin{array}{l}\text { Average } \\
(\mathrm{cm})\end{array}$ & $\begin{array}{l}\text { Standard } \\
\text { deviation }\end{array}$ & $\begin{array}{l}\text { Coefficient of } \\
\text { variation (\%) }\end{array}$ & $\begin{array}{l}\text { Minimum } \\
\quad(\mathrm{cm})\end{array}$ & $\begin{array}{l}\text { Maximum } \\
\quad(\mathrm{cm})\end{array}$ \\
\hline \multicolumn{6}{|c|}{ Dorsal view } \\
\hline Lsk & 23.83 & 2.07 & 8.68 & 21.42 & 27.03 \\
\hline Wcr & 5.44 & 0.38 & 6.02 & 4.76 & 5.78 \\
\hline Lfa & 15.33 & 1.85 & 12.07 & 12.24 & 17.17 \\
\hline Wfa & 8.58 & 0.61 & 7.07 & 7.14 & 9.01 \\
\hline Lna & 9.29 & 0.82 & 8.86 & 8.33 & 10.37 \\
\hline Wna & 3.1 & 0.37 & 12.01 & 2.72 & 3.74 \\
\hline Lfr & 8.05 & 0.82 & 10.21 & 7.31 & 9.69 \\
\hline Lfrs & 5.19 & 0.22 & 4.27 & 4.93 & 5.61 \\
\hline Ls & 3.56 & 0.54 & 15.02 & 3.06 & 4.42 \\
\hline Ws & 12.87 & 0.59 & 4.56 & 12 & 14.11 \\
\hline \multicolumn{6}{|c|}{ Ventral view } \\
\hline LBsk & 23.73 & 1.24 & 5.21 & 22.44 & 25.84 \\
\hline Lpa & 8.42 & 0.33 & 3.87 & 7.99 & 8.84 \\
\hline Wpav & 4.97 & 0.74 & 14.79 & 4.08 & 5.95 \\
\hline $\mathrm{Hfm}$ & 1.69 & 0.29 & 16.72 & 1.36 & 2.04 \\
\hline Wfm & 2.57 & 0.46 & 18.07 & 2.04 & 3.23 \\
\hline \multicolumn{6}{|c|}{ Lateral view } \\
\hline Lo & 4.7 & 0.46 & 9.67 & 3.91 & 5.1 \\
\hline Wo & 4.98 & 0.35 & 7.04 & 4.42 & 5.61 \\
\hline Lpm & 8.75 & 1.14 & 13.06 & 7.48 & 9.86 \\
\hline Lma & 12.32 & 1.74 & 14.11 & 10.71 & 15.13 \\
\hline $\mathrm{Hpm}$ & 1.5 & 0.16 & 10.41 & 1.28 & 1.7 \\
\hline Hma & 7.89 & 0.12 & 1.51 & 7.68 & 7.99 \\
\hline \multicolumn{6}{|c|}{ Nape view } \\
\hline Hoc & 12.24 & 0.27 & 2.23 & 11.9 & 12.58 \\
\hline Wic & 7.84 & 1.03 & 13.18 & 6.46 & 9.69 \\
\hline Wipc & 11.28 & 0.16 & 1.38 & 11.05 & 11.56 \\
\hline Нра & 4.31 & 0.13 & 2.93 & 4.08 & 4.42 \\
\hline Wpan & 10.56 & 0.11 & 1.03 & 10.54 & 10.71 \\
\hline Woc & 8.59 & 1.22 & 14.2 & 7.14 & 10.74 \\
\hline
\end{tabular}

$8.68 \%$ (Lsk, table 1). The longitudinal dimension showed acceptable variability for a breed (less than $10 \%$ according to Parés et al 2010). Regarding the magnitude of Lsk, Agüera et al (1988) reported values of 28.04 and $27.28 \mathrm{~cm}$ for the Spanish Segureña and Merino breeds, respectively, while Parés et al (2010) found $26.55 \mathrm{~cm}$ for the Xisqueta breed, values that are much higher than those observed in this study where even the range of maximum values of the sample did not reach those previously reported by others. On the other hand, the Lsk values obtained in this study outperforms those found in Turkish breeds such as Morkmarán and Tuj (20.44 and $19.80 \mathrm{~cm}$, respectively) or Iranian breeds such as Mehraban $(20.06 \mathrm{~cm})$, which show a fairly high coefficient of variation of $22.58 \%$ (Karimi et al 2011).

However, in this dimension some bones such as the occiput, parietal, frontal, nasal, and premaxilla are totally or partially involved. Therefore, several intermediate parameters are measured.

The length of the parietal bone (Ls) presented an average of $3.56 \mathrm{~cm}$, in a range between 3.06 and $4.42 \mathrm{~cm}$, with a coefficient of variation of $15.02 \%$. This means that this parameter of the cranial area exhibits a variation higher than that acceptable for a racial population (Aparicio 1960), although externally this variation in total length of the head (Lsk) is not observed. Similarly, the frontal bone 
in the longitudinal dimension provides two parameters, Lfrs with an average of $5.18 \mathrm{~cm}$, a range of 4.93 to 5.61 $\mathrm{cm}$, and a coefficient of variation of $4.27 \%$, and Lfr with an average of $8.05 \mathrm{~cm}$, a range of 7.31 to $9,69 \mathrm{~cm}$, and coefficient of variation of $10.20 \%$. Therefore, Lfrs has a low variability and Lfr is at the acceptable limit for a breed. Therefore, it can be seen that, within the appreciable longitudinal dimension from the outside of the animal, there are underlying arrangements of the set of bones that are hidden by the external variability of the head. The Lfr exceeds in magnitude the values for Turkish breeds such as Morkmarán and Tuj (7.37 and $7.00 \mathrm{~cm}$, respectively), their range does not include them because they are larger (Özcan et al 2010), and is lower than those found in the Segureña breed $(9.59 \mathrm{~cm})$ by Parés et al (2010).

The nasal bone, represented by the facial length (Lfa), also intervenes in the longitudinal expression analysed from the dorsal view, reaching an average of $15.32 \mathrm{~cm}$ with a range between 12.24 to $17.17 \mathrm{~cm}$ and coefficient of variation of $12.07 \%$, expressing high morphometric variability. This parameter exceeds in magnitude the values for Turkish breeds such as Morkmarán $(14.03 \mathrm{~cm})$ and Tuj $(13.67 \mathrm{~cm})$ (Özcan et al 2010). It is also higher than the value for the Iranian breed Mehraban $(12.54 \mathrm{~cm})$ which exhibits a coefficient of variation of $9.88 \%$ (Karimi et al 2011).
Finally, the premaxillar bone is also involved through the nasal length (Lna), with an average of $9.29 \mathrm{~cm}$, varying between 8.33 and $10.37 \mathrm{~cm}$ and with a variation coefficient of $8.86 \%$. This parameter was lower than that reported for Turkish breeds such as Morkmarán $(14,03)$ and Tuj $(13.67 \mathrm{~cm})$, (Özcan et al 2010), although it is higher than the value shown by the Iranian race Mehraban $(8.08 \mathrm{~cm})$ which reports a slightly higher coefficient of variation, with $11.75 \%$ (Karimi et al 2011).

Although the total head length (Lsk) showed a normal variability, out of the 5 evaluated parameters intervening in the complex of bones that constitute the longitudinal dimension, three (Ls, Lfr and Lfa) overcome the accepted variability in a well-structured breed population. This suggests that an external expression of low or normal variability does not necessarily indicate that such variability reaches those canons in all the bones that make up that dimension.

When analysing the longitudinal dimension in the ventral view there are three parameters involved, one in the occipital bone area $(\mathrm{Hfm})$, the second between the palatine and maxilla (Lpa) and a longer third, which includes part of the sphenoid, palatal, maxillary, and premaxillary bones (Lbsk) (figure 1). The length of the foramen magnum $(\mathrm{Hfm})$ had an average of $1.68 \mathrm{~cm}$, varying between 1.36 and $2.04 \mathrm{~cm}$ and reaching a variation coefficient of $16.71 \%$, which reveals a high variability for this component. In its

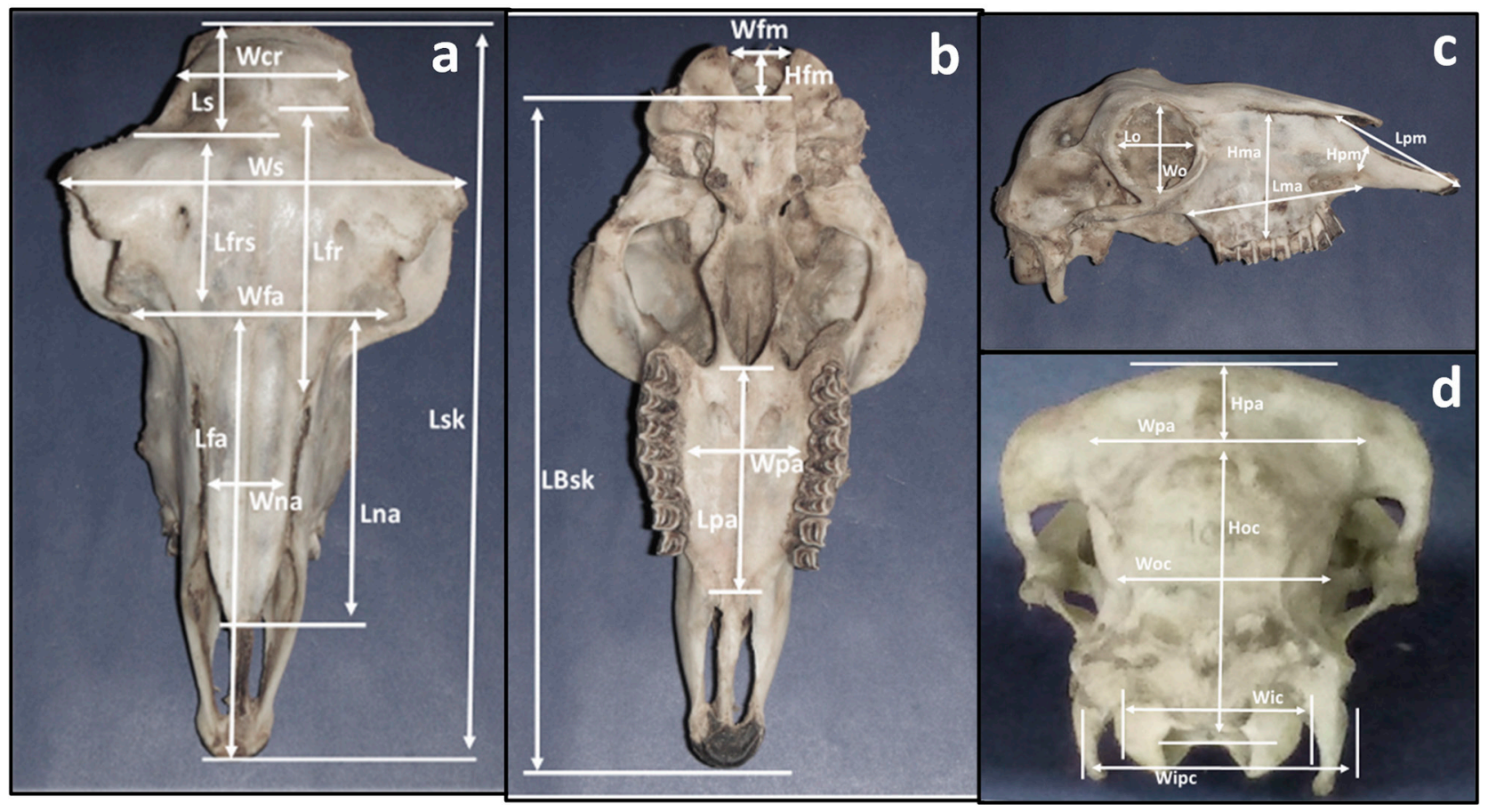

Figure 1. Skull measurements; a) Dorsal view showing skull length (Lsk), cranial width (Wcr), facial length (Lfa), facial width (Wfa), nasal length (Lna), nasal width (Wna), frontal length (Lfr), frontal short length (Lfrs), parietal bone length (Ls) and total head width (Ws); b) Ventral view showing skull length (LBsk), palatine length (Lpa), palatine width (Wpa), height (Hfm) and width (Wfm) of the foramen magnum (Hfm); c) Lateral view showing length of orbit (Lo), width of orbit (Wo), length of premaxilla (Lpm), length of maxilla (Lma), height of premaxilla (Hpm) and height of maxilla Hma; c) Nape view showing height of occipital (Hoc), intercondylar width (Wic), interparacondylar width (Wipc), height of parietal (Hpa), width of parietal (Wpa) and occipital width (Woc). 
magnitude, the foramen magnum length was lower than that of Turkish breeds such as Morkmarán and Tuj (1.94 and $1.78 \mathrm{~cm}$, respectively), but including them in the range (Özcan et al 2010). It is also lower than the value of the Iranian race Mehraban $(1.92 \mathrm{~cm})$, which exhibits a coefficient of variation of $6.25 \%$ (Karimi et al 2011). The palatine length (Lpa) reached an average of 8.41 $\mathrm{cm}$ (range of 7.99 to $8.84 \mathrm{~cm}$ ), showing a low variability with a variation coefficient of $3.87 \%$. The Lbsk parameter, with a length that goes from the ventral rims of the foramen magnum to the rostral margin of the incisive bone, exhibited an average of $23.73 \mathrm{~cm}$ (range of 22.44 to $25.84 \mathrm{~cm}$ ) with a coefficient of variation of $5.20 \%$. In Morkmarán and Tuj sheep, this parameter reaches 18.23 and $17.55 \mathrm{~cm}$, respectively (Özcan et al 2010), and in the Iranian sheep Mehraban is also smaller $(21.48 \mathrm{~cm})$ with a coefficient of variation of $10.01 \%$, which is normal for a breed (Karimi et al 2011), while in Xisqueta breed it is $22.31 \mathrm{~cm}$ (Parés et al 2010). These data indicate a higher value for these breeds. In the context of a cephalic total length (Lsk) it exhibits normal to low variability. In the case of Lbsk, the Xisqueta sheep shows a coefficient of variation of $3.2 \%$ (Parés et al 2010), suggesting that in the bone complex that intervenes in the longitudinal dimension, the low variability of some parameters may hide the high variability of others or vice versa, being part of the plasticity proposed by Thomason et al (2001).

Three parameters intervene in the side view, which are the length of the eye socket (Lo), the length of the premaxilla (Lpm), and the length of the maxilla (Lma) (figure 1). Lo exhibited an average of $4.70 \mathrm{~cm}$ (range of 3.91 to $5.10 \mathrm{~cm}$ ) with a coefficient of variation of $9.67 \%$. In its magnitude, Lo exceeded Turkish breeds such as Morkmarán and Tuj (3.61 and $3.66 \mathrm{~cm}$, respectively) and its range was higher, and therefore it does not include them (Özcan et al 2010). ). It is also higher than the value in the Iranian breed Mehraban $(3.64 \mathrm{~cm})$, which exhibits a coefficient of variation of $5.76 \%$ (Karimi et al 2011). The length of the premaxilla showed an average of $8.75 \mathrm{~cm}$ (range of 7.48 to $10.20 \mathrm{~cm}$ ), with a coefficient of variation of $13.05 \%$. In its magnitude, the Lpm exceeded the mentioned Turkish breeds (6.22 and $5.85 \mathrm{~cm}$, respectively) and its rank does not include them because it is higher (Özcan et al 2010). On the other hand, the length of the maxilla (Lpm) showed an average of $12.31 \mathrm{~cm}$ (range of 10.88 to $15.13 \mathrm{~cm}$ ) with a coefficient of variation of $14.01 \%$. In this case, one of the three parameters (Lo) exhibited a normal variability, while the other two (Lpm and Lma) showed high variability. The parameters of the nape view do not influence the longitudinal dimension.

A second dimension is given by the total head width (Ws), which reached a dorsal view average (figure 1) of $12.87 \mathrm{~cm}$ (range 12.0 to $14.11 \mathrm{~cm}$ ), with a coefficient of variation of $4.56 \%$ (table 1 ), showing low variability than desirable for a well-structured breed population. This dimension is higher than that observed in Iranian Mehraban sheep $(10.44 \mathrm{~cm})$, which also exhibit a reduced coefficient of variation of $7.37 \%$ (Karimi et al 2011). It is interesting to note that, in dorsal view, the width only involves the frontal bone. In this dimension, three parameters were evaluated: the cranial width parameter (Wcr), with a mean value of $5.44 \mathrm{~cm}$ (range 4.76 to $5.78 \mathrm{~cm}$ ), with a coefficient of variation of $6.02 \%$ (figure 1 ; table 1 ); the facial width (Wfa), which partially incorporates the frontal and lacrimal bone and exhibited a mean (figure 1) of $8.58 \mathrm{~cm}$ (range of 7.14 to $9.01 \mathrm{~cm}$ ) with a coefficient of variation of 7.07 (table 1). The value is lower than that of Mehraban $(10.68 \mathrm{~cm})$, which exhibits a similar coefficient of variation (7.20\%) (Karimi et al 2011), and finally, the nasal width (Wna) involving only the nasal bone, that showed a mean (figure 1) of $3.10 \mathrm{~cm}$ (range 2.72 to $3.74 \mathrm{~cm}$ ) with a coefficient of variation of $12.00 \%$ (table 1 ). The value is higher than the value thrown by the Mehraban breed $(2.88$ $\mathrm{cm}$ ), which exhibits a coefficient of variation of $13.54 \%$ (Karimi et al 2011).

In the dorsal view of the three parameters evaluated, two showed low variability (Wcr and Wfa), while Wna had a variability of over $10 \%$.

The dimension of the width in the ventral view was evaluated through two parameters: the width of the palatine (Wpav) and the width of the foramen magnum (Wfm). The width of the palatal (Wpav), which involves as its name indicates the palatal bone, but also partially to the maxilla, exhibited a mean (figure 1) of $4.97 \mathrm{~cm}$ (range of 4.08 to $5.95 \mathrm{~cm}$ ) with a coefficient of variation of $14.79 \%$ (table 1). On the other hand, the width of the foramen magnum (Wfm), which only involves the occipital bone, showed a mean (figure 1) of $2.57 \mathrm{~cm}$ (range of 2.04 to $3.23 \mathrm{~cm}$ ) with a coefficient of variation of $18.07 \%$ (table 1). The reference shown by Mehraban breed (1.97 $\mathrm{cm})$, is smaller and exhibits a coefficient of variation also smaller $(6.59 \%)$ (Karimi et al 2011). A high variability at the width of the palatal and the foramen magnum was appreciated in the ventral view.

The analysis of the lateral view only considered the analysis of the width of the ocular orbit (Wo), which involves the frontal, zygomatic, and lacrimal bone. This parameter showed a mean (figure 1) of $4.98 \mathrm{~cm}$ (range of 4.42 to $5.61 \mathrm{~cm}$ ) with a variation coefficient of $7.04 \%$ (table 1). The value is slightly lower than that of the Mehraban sheep $(5.11 \mathrm{~cm})$, which exhibited a coefficient of variation of $9.98 \%$ (Karimi et al 2011). The occipital, parietal and interparietal bones participate in the nape view (figure 1). Four parameters were evaluated; the parietal width (Wpan), the occipital width (Woc), the intercondylar width (Wic) and the interparacondylar width (Wipc). The parietal width (Wpan) showed a mean (figure 1) of 10.56 $\mathrm{cm}$ (range 10.37 to $10.71 \mathrm{~cm}$ ) with a coefficient of variation of $1.03 \%$ (table 1), that is, practically without variation. The occipital width (Woc) exhibited a mean (figure 1) of $8.59 \mathrm{~cm}$ (range 7.14 to $10.71 \mathrm{~cm}$ ) with a coefficient of variation of $14.20 \%$ (table 1). On the other hand, the 
intercondylar width (Wic), showed a mean (figure 1) of 7.84 $\mathrm{cm}$ (range 6.46 to $9.69 \mathrm{~cm}$ ) with a coefficient of variation of $13.18 \%$ (table 1). This parameter broadly exceeded Turkish breeds such as Morkmarán and Tuj (4.41 and 4.45 $\mathrm{cm}$, respectively), and the range also exceeds them (Özcan et al 2010). Finally, the interparacondylar width (Wipc) reached a mean (figure 1) of $11.28 \mathrm{~cm}$ (range of 11.05 to $11.56 \mathrm{~cm}$ ) with a coefficient of variation of $1.38 \%$ (table 1). For this parameter, the measurements also exceed those of the Turkish breeds (5.78 and $5.72 \mathrm{~cm}$, respectively), and even the range excludes them (Özcan et al 2010). In this dimension of the nape view, there was wide variability in the occipital (Woc) and intercondylar (Wic) width. In contrast, the parietal width (Wpan) and the interparacondylar width (Wipc) showed a very low variability.

In the cephalic altitudinal dimension, the dorsal dimension and ventral view do not intervene. In the side view, two parameters that can affect the height are considered: the height of the premaxilla (Hpm) and the height of the maxilla (Hma). The height of the premaxilla $(\mathrm{Hpm})$ showed a mean (figure 1) of $1.49 \mathrm{~cm}$ (range of 1.28 to $1.70 \mathrm{~cm}$ ) with a coefficient of variation of $10.40 \%$ (table 1 ). On the other hand, the height of the maxilla (Hma) had a mean (figure 1) of $7.89 \mathrm{~cm}$ (range of 7.68 to $7.99 \mathrm{~cm}$ ) with a coefficient of variation of $1.51 \%$ (table 1 ). The first shows variability in the acceptable limit for one breed, and the second a very low variability.

The dorsal and ventral view does not intervene in the cephalic altitudinal dimension. In the side view, two parameters that can affect the height were considered, the height of the premaxilla (Hpm) and the maxilla (Hma). $\mathrm{Hpm}$ showed a mean (figure 1) of $1.49 \mathrm{~cm}$ (range 1.28 to $1.70 \mathrm{~cm}$ ) with a coefficient of variation of $10.40 \%$ (table 1 ), in the acceptable limit for one breed. On the other hand, Hma showed a mean (figure 1) of $7.89 \mathrm{~cm}$ (range 7.68 to $7.99 \mathrm{~cm}$ ) with a very low coefficient of variation $(1.51 \%)$ (table 1).

The cephalic height analysed from the nuchal view considers the intervention of the occipital and parietal bones and is carried out through the measurement of two parameters, the occipital (Hoc) and parietal (Hpa) height (figure 1). Hoc showed a mean (figure 1) of $12.24 \mathrm{~cm}$ (range 11.90 to $12.58 \mathrm{~cm}$ ) with a coefficient of variation of $2.22 \%$ (table 1). Hpa exhibited a mean (figure 1) of 4.31 $\mathrm{cm}$ (range 4.08 to $4.42 \mathrm{~cm}$ ) with a coefficient of variation of $2.93 \%$ (table 1), both parameters having low variability.

There are not many specific studies carried out on cranial parameters in sheep; however, there are relevant differences between the different breeds, suggesting the need for further investigations. Since the bibliography reports a high cranial variability intraspecies, this is a relevant aspect to consider because a significant number of studies to characterise sheep breeds use cranial measurements (Rodríguez et al 1990, Álvarez et al 2000, Riva et al 2004, Özcan et al 2010, Parés et al 2010, Latorre et al 2011, Mujica et al 2012). In this sense, indexes such as cranial or cephalic are used to describe the potential or productive specialisation of a sheep breed (Bravo and Sepúlveda 2010, De la Barra et al 2016, Baranowsky 2017).

However, it is possible to speculate that since the bone structure would be less influenced by specific environmental effects (Parés et al 2010, Özcan et al 2010, Ilayperuma, 2011, Mohamed et al 2016), complex bone arrangements could be made that allow the animal to acquire a biomechanical functionality through the plastic adaptation of the cranial components, generating an immediate adjustment mechanism, beyond the genetic variability of each bone separately (Thomason et al 2001). From this point of view, the cranial dimensions are still useful in defining the productive potential of a sheep population; however, they should be taken with caution for racial definitions, where the individual variability of the bones could be a better reflection of the genetic structure of the population.

Finally, regarding the analysed data, it is not possible to state that the externally observable variability in the cranial area of a sheep can be projected to each of the bone components of this area, whether in length, width, or height dimensions. Therefore, it is possible to observe that the external variability might contrast with the variability of the individual bones that participate in a certain dimension. A more comprehensive and multivariate analysis could be required to analyse the underlying shape to perform more precise analyses (Salako 2006, Toro et al 2010). However, it can be speculated that, since the bone structure would be less influenced by specific environmental effects (Parés et al 2010, Özcan et al 2010, Ilayperuma 2011, Mohamed et al 2016), complex bone arrangements could be made, that allow the animal to acquire a biomechanical functionality through the plasticity or a mechanism of adaptation of the cranial components, generating an immediate adjustment mechanism, beyond the genetic variability of each bone separately (Thomason et al 2001). From this point of view, the cranial dimensions are still useful in defining the productive potential of a sheep population; however, they should be taken with caution for breed definition purposes, where the individual variability of the bones could be a better reflection of the genetic structure of the population instead of the dimensional variability, which could have a relevant environmental bias.

It is concluded that it is not possible to affirm that the externally observable variability in the cranial area of a sheep can be projected to each one of the bony components of the cranial zone, whether in the dimension of length, width, or height. It was observed that the variability of a cephalic dimension, whether to the length, width or height, can be contrasted with the variability of the individual bones that participate in a given dimension as part of a mechanism of wide plasticity or adjustment, independent of the genetic variability of each bone separately. The cranial dimensions are still useful in defining the productive potential of a sheep population; however, they should be taken with caution for breed definition purposes, where 
the individual variability of the bones could be a better reflection of the genetic structure of the population, and the dimensionality could be biased by adaptive plasticity.

\section{REFERENCES}

Agüera S, Castejón F, Diaz A, Miró F, López Rivero J. 1988. Diferenciación radiológica en ovejas manchegas y merinas. Archivos de Zootecnia 37, 205.

Alvarez S, Fresno M, Capote J, Delgado J, Barba C. 2000. Estudio para la caracterización de la Raza ovina Canaria. Archivos de Zootecnia 49, 209-215.

Aparicio G. 1960. Zootecnia especial. Etnología compendiada. Imprenta Moderna, Córdoba, Argentina.

Baranowsky P. 2017. Craniometric characteristics and cranial indices of Polish Heath sheep rams - extended data. Int J Morphol 35, 133-140.

Bravo S, Sepúlveda N. 2010. Indices zoométricos en ovinos criollos Araucanos. Int J Morphol 28, 489-495.

Brüenner H, Lugon-Moulin N, Balloux F, Fumagalli L, Hausser J. 2002. Taxonomical re-evaluation of the Valais chromosome race of the common shrew. Sorex araneus (Insectivora: Soricidae). Acta Theriol 47, 245-275.

Carneiro H, Louvandini H, Paiva S, Macedo F, Mernies B, et al. 2010. Morphological characterization of sheep breeds in Brazil, Uruguay and Colombia. Small Rum Res 94, 58-65.

Chirinos Z. 2011. La funcionalidad animal, herramienta esencial para el mejoramiento del rebaño bovino. In: Innovación y tecnología de la ganadería doble propósito. Universidad del Zulia, Zulia, Venezuela, Pp 217-223.

Choudhary P, Singh I. 2016. Morphological and radiographic studies on the skull of Indian blackbuck (Antilope cervicapra). Int J Morphol $34,775-783$.

Cobb S, O'Higgins P. 2007. The ontogeny of sexual dimorphism in the facial skeleton of the African apes. J Hum Evol 53, 176-190.

De la Barra R, Martínez ME, Carvajal AM. 2016. Morphostructural relationships and productive functionality of sheep breeds used for terminal crossbreeding in Chile. Int J Morphol 34, 958-962.

Herrera M, Luque M. 2009. Morfoestructura y sistemas para el futuro en la valoración morfológica. In: Sañudo AC (ed). Valoración morfológica de los animales domésticos. Ministerio de Medio Ambiente y Medio Rural y Marino, Madrid, España, Pp 79-109.

Ilayperuma I. 2011. Evaluation of cephalic indices: A clue for racial and sex diversity. Int J Morphol 29, 112-117.

Karimi I, Onar V, Pazvant G, Hadipour M, Mazaheri Y. 2011. The mranial morphometric and morphologic characteristics of Mehraban sheep in Western Iran. Global Veterinaria 6, 111-117.

Latorre E, Uribe H, Martínez ME, Calderón C, De la Barra R. 2011. Morphology differentiation and structural functionality of ewes due to uncomplete crossbreeding. Int J Morphol 29, 954-959.
Macedo R, Arredondo V, Cervantes A. 2016. Head and tail morphology of Pelibuey, Katahdin and Blackbelly rams in Colima, México. Vet México 3, 1-9.

Miró F, Diaz A, López-Rivero J, Regodon S. 1988. Determinación de algunos parámetros cefálicos del vacuno de raza Retinta. Arch Zootec 37, 75 .

Mohamed R, Driscoll M, Mootoo N. 2016. Clinical anatomy of the skull of the Barbados Black Belly sheep in Trinidad. Int J Curr Res Med Sci 2, 8-19.

Mujica F, Mella J, De la Barra R, Blanco A. 2012. Phenotipic characterization of the sheep breed Creole Chilota and two sheep breeds that predominate in southern Chile. Actas Iberoamericanas de Conservación Animal 2, 67-70.

Olopade J, Onwuka S. 2004. Morphometric studies of the cranio-facial region of the West African Dwart goat in Nigeria. Int J Morphol $22,145-148$

Özcan S, Aksoy G, Kürtul I, Aslan K, Özüdogru, Z. 2010. A comparative morphometric study on the skull of the Tuj and Morkaraman sheep. Kafkas Univ Vet Fak Derg 16, 111-114.

Parés I, Kamal S, Jordana J. 2010. On biometrical aspects of the cephalic anatomy of Xisqueta sheep (Catalunya, Spain). Int J Morphol 28, 347-351.

Popoola MA, Oseni SO. 2018. Multifactorial discriminant analysis of cephalic morphology of indigenous breeds of sheep in Nigeria. Slovak J Anim Sci 51, 45-51.

Ravosa M, Noble V, Hylander W, Johnson K, Kowalski E. 2000. Masticatory stress, orbital orientation and the evolution of the primate postorbital bar. J Human Evol 38, 667-693.

Riva J, Rizzi R, Marelli S, Cavalchini L. 2004. Body measurements in Bergamasca sheep. Small Rum Res 55, 221-227.

Rodríguez P, Tovar J, Rota A, Rojas A, Martín L. 1990. El exterior de la cabra Verata. Archivos de Zootecnia 43, 57.

Salako A. 2006. Application of morphological indexes in the assessment of type and function in sheep. Int J Morphol 24, 13-18.

Sánchez-Belda A. 1964. Merinos entrefinos. Fomento y mejora del ganado lanar. Ministerio de Agricultura, Madrid, España.

Sierra I. 2001. El concepto de raza: evolución y realidad. Archivos de Zootecnia 50, 547-564.

Sotillo J, Serrano V. 1985. Producción animal. Etnología zootécnica. Tomo I. Imprenta Flores, Albacete, España, Pp 111-116.

Thiagarajan R, Jayashankar M. 2012. Effect of genetic and no genetic factors on staple length in indigenous and crossbreed sheep. Research Journal of Animal Sciences 6, 1-3.

Thomason J, Grovum L, Deswysen A, Bignell W. 2001. In vivo surface strain and stereology of the frontal and maxillary bones of sheep: Implications for the structural design of the mammalian skull. The Anatomical Record 264, 325-338.

Toro I, Manríquez S, Suazo G. 2010. Morfometría geométrica y el estudio de las formas biológicas: De la morfología descriptiva a la morfología cuantitativa. Int J Morphol 28, 977-990. 
